\title{
Pulmonary and hemostatic toxicity of multi-walled carbon nanotubes and zinc oxide nanoparticles after pulmonary exposure in Bmal1 knockout mice
}

Katrien Luyts ${ }^{1}$, Stijn Smulders ${ }^{1}$, Dorota Napierska ${ }^{1}$, Soetkin Van kerckhoven ${ }^{2}$, Katrien Poels ${ }^{3}$, Hans Scheers ${ }^{1}$, Bianca Hemmeryckx², Ben Nemery ${ }^{1}$, Marc F Hoylaerts ${ }^{2}$ and Peter $\mathrm{H} \mathrm{M} \mathrm{Hoet}^{1 *}$

\begin{abstract}
Background: Pulmonary exposure to nanoparticles (NPs) may affect, in addition to pulmonary toxicity, the cardiovascular system such as procoagulant effects, vascular dysfunction and progression of atherosclerosis. However, only few studies have investigated hemostatic effects after pulmonary exposure.
\end{abstract}

Methods: We used Bmal1 (brain and muscle ARNT-like protein-1) knockout (Bmal1 ${ }^{-/}$) mice which have a disturbed circadian rhythm and procoagulant phenotype, to study the pulmonary and hemostatic toxicity of multi-walled carbon nanotubes (MWCNTs) and zinc oxide (ZnO) NPs after subacute pulmonary exposure. Bmal $1^{-1-}$ and wild-type $\left(B \mathrm{Bal}^{+/+}\right)$mice were exposed via oropharyngeal aspiration, once a week, during 5 consecutive weeks, to a cumulative dose of 32 or $128 \mu \mathrm{g}$ MWCNTs or 32 or $64 \mu \mathrm{g}$ ZnO NPs.

Results: MWCNTs caused a pronounced inflammatory response in the lung with increased cell counts in the broncho-alveolar lavage and increased secretion of interleukin-1 $\beta$ and cytokine-induced neutrophil chemo-attractant (KC), oxidative stress (increased ratio of oxidized versus reduced glutathione and decreased total glutathione) as well as anemic and procoagulant effects as evidenced by a decreased prothrombin time with increased fibrinogen concentrations and coagulation factor (F)VII. In contrast, the ZnO NPs seemed to suppress the inflammatory (decreased neutrophils in Bmal $1^{-/}$mice) and oxidative response (increased total glutathione in Bmal1 ${ }^{-/-}$mice), but were also procoagulant with a significant increase of FVIII. The procoagulant effects, as well as the significant correlations between the pulmonary endpoints (inflammation and oxidative stress) and hemostasis parameters were more pronounced in Bmal $1^{-/-}$mice than in Bmal1 $1^{+/+}$mice.

Conclusions: The Bmal1 $1^{-/}$mouse is a sensitive animal model to study the procoagulant effects of engineered NPs. The MWCNTs and ZnO NPs showed different pulmonary toxicity but both NPs induced procoagulant effects, suggesting different mechanisms of affecting hemostasis. However, the correlation analysis suggests a causal association between the observed pulmonary and procoagulant effects.

Keywords: Bmal ${ }^{-/-}$mice, Procoagulant phenotype, Subacute study, Hemolysis, Zinc-induced inflammatory suppression

\footnotetext{
* Correspondence: peter.hoet@med.kuleuven.be

${ }^{1}$ Department of Public Health and Primary Care, Occupational and

Environmental Toxicology, KU Leuven, Leuven, Belgium

Full list of author information is available at the end of the article
} 


\section{Background}

The rapid developments in nanotechnologies have increased the production of nanoparticles (NPs). These engineered NPs are, due to their unique physico-chemical properties, currently incorporated in thousands of products in a broad range of industries. This leads to an increased risk of exposure in occupational and environmental settings [1]. Obviously, the lungs are an important target for toxicity studies since it is the main exposure route and site of particle deposition. However, the effects are probably not limited to the respiratory tract, since environmental ultrafine particles (UFP) can cause cardiovascular toxicity/morbidity and lately, similar observations have been made for NPs [2].

Epidemiological studies showed associations between environmental particulate matter exposure and atherosclerosis and an increased risk for myocardial infarction $[3,4]$. People living near ( $<245$ meters) a major traffic road have an increased risk for deep vein thrombosis [5]. These effects are even more pronounced in human populations with underlying cardiovascular disease or risk factors (diabetes mellitus, hypertension, heart failure) [6-9]. Experimental animal models established that pulmonary titanium dioxide $\left(\mathrm{TiO}_{2}\right)$ NP exposure significantly impairs endothelium-dependent vasoreactivity in rat coronary arterioles [10]. Intratracheal administration of aminated polystyrene NPs $(5 \mathrm{mg} / \mathrm{kg})$ significantly increased thrombus formation in the femoral vein in a hamster model [11]. Subchronic exposure to low doses of single-walled carbon nanotubes (SWCNT) and multiwalled carbon nanotubes (MWCNT) resulted in accelerated plaque formation in apo lipoprotein $\mathrm{E}$ knockout $\left(\mathrm{ApoE}^{-/-}\right)$mice $[12,13]$.

Bmal1 (brain and muscle ARNT-like protein) is a basic helix-loop-helix-PAS domain-containing transcription factor and is, together with another member of this family, CLOCK, the key component of the molecular oscillator that generates circadian rhythms $[14,15]$. The central component of the circadian clock is located in the hypothalamic suprachiasmatic nucleus (SCN), near the optic chiasm. Environmental information (light/dark) received via the retina synchronizes the internal clock, and the $\mathrm{SCN}$, in its turn, synchronizes the activity of peripheral oscillators present in every cell of an organism. These peripheral oscillators generate rhythms in gene expression, metabolism, and hormone secretion which ultimately result in rhythmic changes in physiology and behavior, presumably as an adaptation to the daily changes in the environment [16]. Mice with a dysfunctional circadian clock lacking the Bmal1 gene have been shown to have a prothrombotic state due to increased platelet aggregation and adhesion, compared to $\mathrm{Bmal1}^{+/+}$mice [17]. They display vascular disease with endothelial dysfunction due to hyperactivated endothelial cells and an impaired endothelium-dependent vasorelaxant response [18,19]. $\mathrm{Bmal1}^{-/-}$mice have an average lifespan of $37.0 \pm 12.1$ weeks and spontaneous deaths start at the age of 26 weeks. Also, some phenotypical changes associated with premature ageing are present such as the development of cataracts (starting at the age of only 18 weeks), decreased adipose and muscle tissue mass compared to $B$ mall $1^{+/+}$mice and reduced hair growth [20].

These observed phenotypes are caused by the deregulation of reactive oxygen species (ROS). Bmal1 directly regulated ROS and its deficiency leads to an excessive ROS production, leading to chronic oxidative stress [20]. The role of oxidative stress in the early onset of ageing in $\mathrm{Bmal1}^{-/-}$mice has been proven by the increased life span due to the dietary supplementation of the antioxidant $\mathrm{N}$-acetyl cysteine (NAC). Also the development of cataracts was attenuated, but growth retardation, reduced hair regrowth, sarcopenia and joint ossification were not affected by NAC administration suggesting the involvement or other mechanisms besides oxidative stress for the increased ageing [21]. Several clinical conditions have been linked to chronic oxidative stress, including cardiovascular disease. An excessive stimulation of $\mathrm{NAD}(\mathrm{P}) \mathrm{H}$ oxidase activity by cytokines or other agents drives the increased ROS levels and are often associated with pathological changes indicative of a deregulation of signaling cascades and/or gene expression [22].

The Bmal1 $1^{-/-}$mouse has phenotypic characteristics of people with cardiovascular disease which are driven by oxidative stress and it is therefore believed to be a good model to study extra-pulmonary toxicity such as effects on coagulation and the vasculature, after pulmonary exposure to NPs. Additional to the role of the Bmal1 gene in the cardiovascular system, the Bmal1 ${ }^{-/-}$mouse model previously has been used for research regarding osteogenesis, myogenesis, insulin resistance and obesity [23-25].

In order to assess whether Bmal1 ${ }^{-1-}$ mice are more prone to the adverse effects of pulmonary administered NPs, we subacutely exposed $\mathrm{Bmal}^{-/-}$and $\mathrm{Bmal1}^{+/+}$mice to MWCNT or ZnO NPs, via oropharyngeal aspiration. 24 hours or 8 weeks after the last administration, we assessed pulmonary inflammation and oxidative stress together with effects on blood cell counts, coagulation status and the early onset of vascular inflammation (macrophage influx).

\section{Results}

\section{Broncho-alveolar lavage}

The total amount of cells in the broncho-alveolar lavage (BAL) fluid, and the fraction of macrophages, neutrophil, eosinophils and lymphocytes herein were calculated for each mouse. In general, the total BAL cell numbers more than doubled $(\mathrm{p}=0.001)$ after administration of MWCNT without difference between the two dose 
groups (Figure 1A). In the Bmal1 $1^{-/-}$mice, however, the total number of BAL cells was lower after the high MWCNT dose compared to the low MWCNT dose (confirmed by the concentration $\mathrm{x}$ genotype interaction of principal component $1 ; \mathrm{p}=0.015$ ). The number of BAL cells, after MWCNT treatment was significantly higher after 24 hours (T1) compared to 8 weeks later (T2) $(p=0.002)$. The same trends were observed for the $\mathrm{ZnO} \mathrm{NPs}$, however, the differences were less pronounced and not significant (Figure 1E). The macrophages made up the largest fraction of BAL cells and followed the same pattern as the total amount of BAL cells. For the MWCNTs, the neutrophils also followed the same pattern as the total BAL cell count (Figure 1B). However, the $\mathrm{ZnO}$ NPs caused, at $\mathrm{T} 1$, a neutrophil increase in Bmal1 ${ }^{+/+}$mice, but a neutrophil decrease in $\mathrm{Bmal1}^{-/-}$mice (concentration $\mathrm{x}$ genotype interaction: $\mathrm{p}=0.04$; Figure $1 \mathrm{~F})$. Also, the highest numbers of neutrophils were found at T1 as compared to T2 $(\mathrm{p}=0.004$ for MWCNT and $\mathrm{p}=0.02$ for $\mathrm{ZnO}$ NPs) and these were generally higher in the Bmal1 ${ }^{-/-}$mice than in $B$ mal1 ${ }^{+/+}$ mice ( $\mathrm{p}=0.009$ for MWCNT) (data not shown).

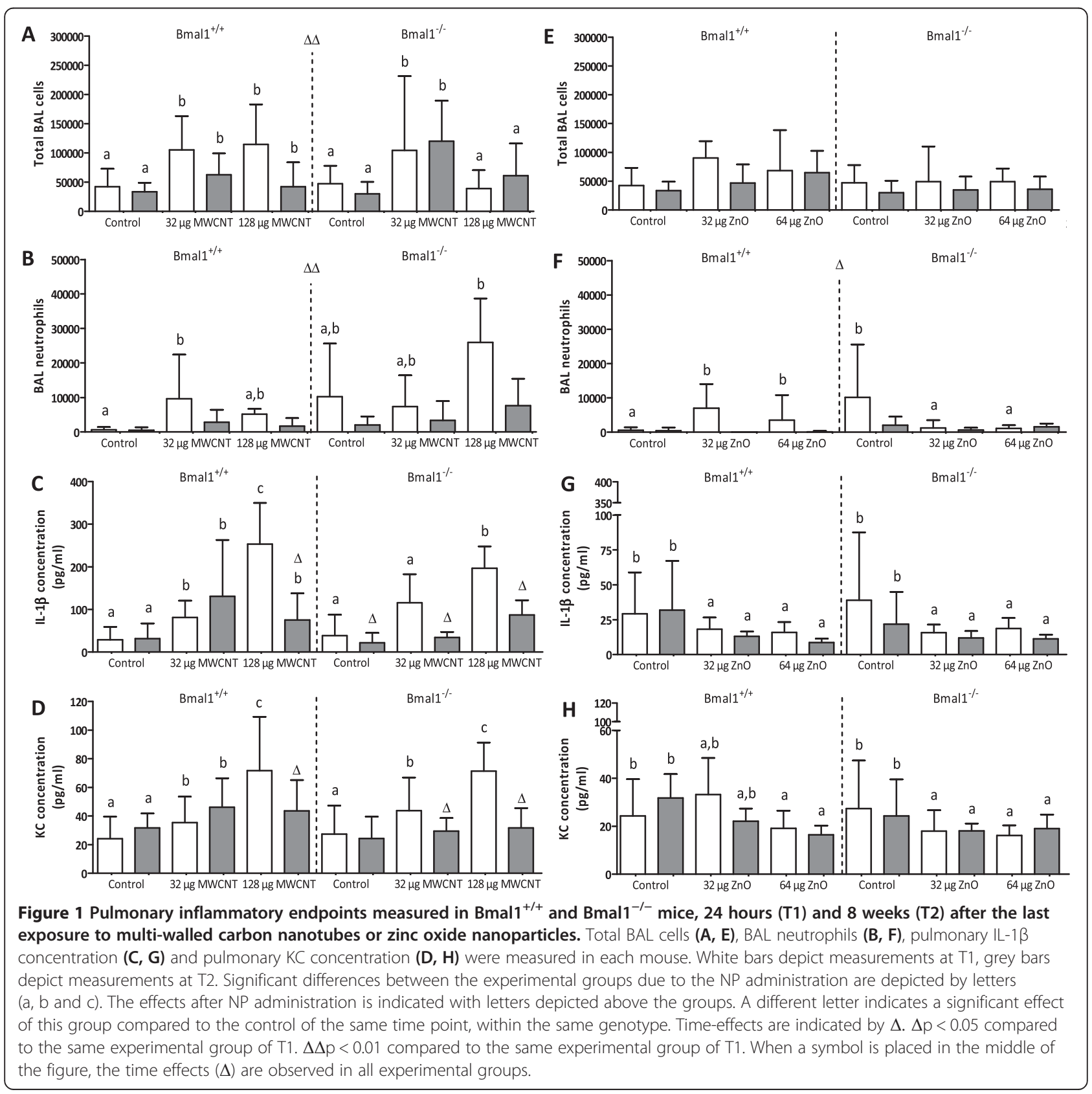


A principal component analysis (PCA) taking into account the cellular influx in the lung showed a positively correlation with all 5 variables (total BAL cells and the number of each cell type) and accounted for 55\% and 52\% of the total variability for MWCNT $(\mathrm{p}=0.0005)$ and $\mathrm{ZnO}$ NPs $(p=0.008)$, respectively. Results using PCA were very similar to those of the total cell counts (data not shown).

The BAL macrophages show evidence of internalized MWCNTs up to T2 for both concentrations and both genotype (Figure 2). Data are only shown for the Bmal1 ${ }^{-/-}$ mice. On the other hand, the $\mathrm{ZnO}$ NPs were not visible in these cells. A summary of the data can be found in Table 1 .

\section{Cytokines in lung homogenates}

From the panel of pro-inflammatory cytokines measured, only the levels of IL-1 $\beta$ and $K C$ were above the lower limit of detection. Administration of MWCNTs dose-dependently increased IL-1 $\beta(\mathrm{p}<0.001)$ and $\mathrm{KC}$ $(\mathrm{p}<0.001)$ secretion in the lungs (Figures $1 \mathrm{C}$ and $1 \mathrm{D})$. At T2 evidence of an inflammatory response was still present (increased IL-1 $\beta$ levels). Administration of the $\mathrm{ZnO}$ NPs did not have significant effects on the cytokine secretion. At T2, the $\mathrm{KC}$ levels in the exposed groups were decreased in the $\mathrm{Bmal1}^{+/+}$mice, but increased in the $\mathrm{Bmal1}^{-/-}$mice (three-way interaction, $\mathrm{p}=0.023$ ). A summary of the data can be found in Table 1 .

\section{Pulmonary oxidative stress}

Exposure to MWCNTs decreased the total glutathione concentrations (T1: $57.1 \%$ of the control, T2: $78.5 \%$ for $\mathrm{Bmal1}^{+/+}$mice; T1: $68.2 \%$, T2: $74.7 \%$ for $\mathrm{Bmal1}^{-/-}$mice; $\mathrm{p}=0.0001$ ) with levels being higher for the $\mathrm{Bmal1}^{+/+}$ mice than the $\mathrm{Bmal1}^{-/-}$mice $(\mathrm{p}=0.034)$ (Figure $3 \mathrm{~A}$ ). The GSSG/GSH ratio increased after MWCNT administration (T1: $172.8 \%$, T2: $211.4 \%$ for $\mathrm{Bmal1}^{+/+}$mice, T1: 133.1\%, T2: $90 \%$ for $\mathrm{Bmal1}^{-/-}$mice; $\mathrm{p}=0.005$ ) and was higher at $\mathrm{T} 1(\mathrm{p}=0.003)$ than at $\mathrm{T} 2$ (Figure $3 \mathrm{~B})$. The $\mathrm{ZnO}$ NPs increased the total amount of glutathione in the lungs (T1: $101.5 \%$, T2: $127.6 \%$ for $\mathrm{Bmal1}^{+/+}$mice; T1: $242.8 \%$, T2: $148.7 \%$ for Bmal1 $1^{-1-}$ mice; $\mathrm{p}=0.0002$ ), with values being highest at $\mathrm{T} 1$ compared to $\mathrm{T} 2$, again only in the Bmal1 ${ }^{-1-}$ mice (time $\mathrm{x}$ genotype interaction, $\mathrm{p}=0.028$ ) (Figure $3 \mathrm{C}$ ). The GSSG/GSH ratio significantly decreased (Figure 3D) after $\mathrm{ZnO}$ NP exposure (T1: $7.1 \%$, T2: $52.9 \%$ for $\mathrm{Bmal1}^{+/+}$mice, $\mathrm{T} 1: 3.3 \%$, T2: $27.8 \%$ for Bmal1 ${ }^{-/-}$mice; $\left.\mathrm{p}<0.0001\right)$.

\section{Blood cell counts}

The total counts of white blood cells (WBC) significantly differed between the genotypes, with the $\mathrm{Bmal1}{ }^{-/-}$mice having significantly higher WBC values compared to the Bmal1 $^{+/+}$mice $(\mathrm{p}=0.002$ for MWCNTs and $\mathrm{p}<0.0001$ for $\mathrm{ZnO}$ NPs), but no effect of NP administration on the WBC levels could be detected (data not shown). The

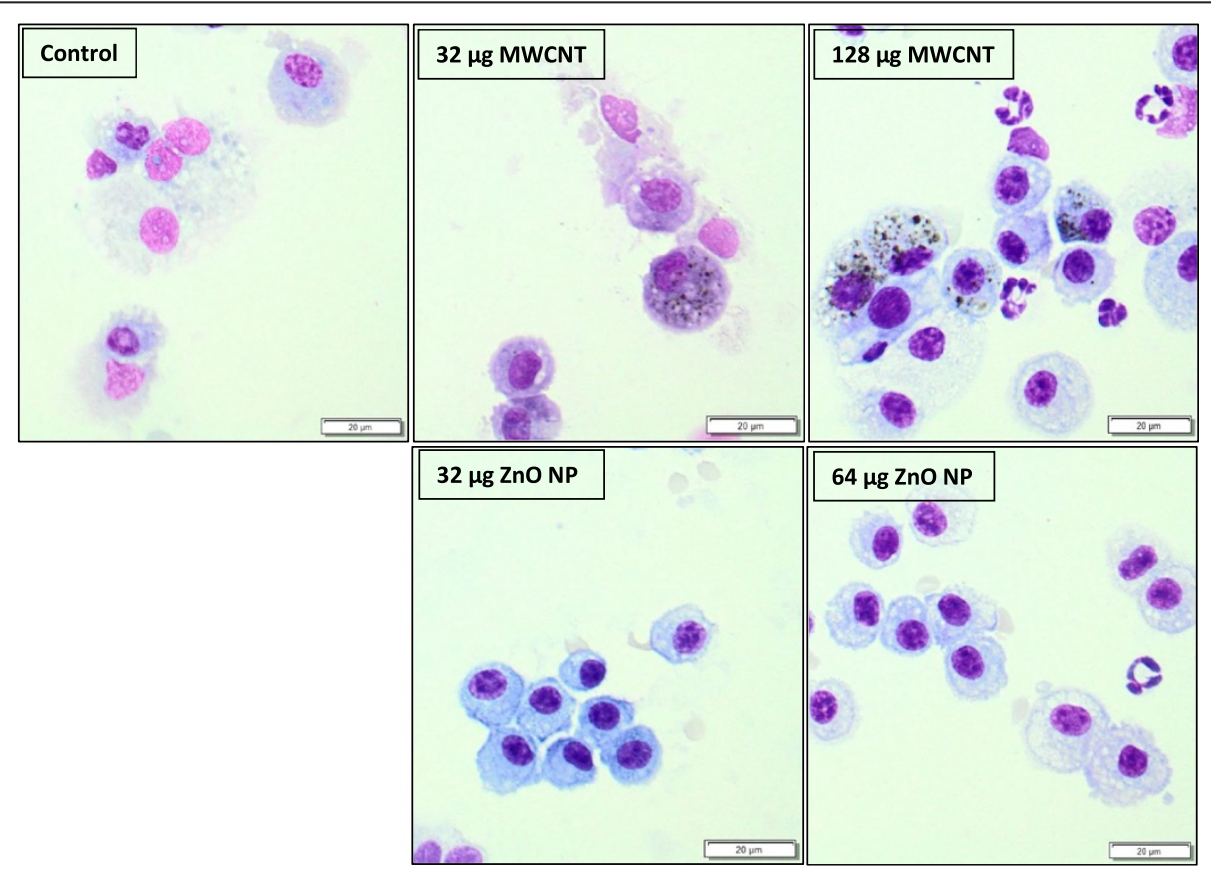

Figure 2 BAL cells of Bmal1 ${ }^{-/-}$mice exposed to MWCNTs and ZnO NPs. Both groups receiving the low and high dose of MWCNT showed CNT-laden macrophages in the BAL 8 weeks after the last administration (T2) whereas the BAL cells of the mice exposed to the ZnO NPs did not show - at this magnification - any inclusions of particulate material. 
Table 1 Summary of the nanoparticle-induced, genotype and time effects

\begin{tabular}{lcccc}
\hline & MWCNT & ZnO & $\begin{array}{l}\text { Genotype } \\
\text { effect }\end{array}$ & Time effect \\
\hline Pulmonary toxicity: & & & & \\
BAL cells & $\uparrow \uparrow$ & $\approx$ & $\approx$ & $\downarrow$ (only WT) \\
Lung cytokines & $\uparrow \uparrow$ & $\downarrow$ & $\approx$ & $\downarrow$ \\
Oxidative stress & $\uparrow \uparrow$ & $\downarrow$ & $\downarrow$ & $\downarrow$ \\
Extra-pulmonary toxicity: & & & & \\
Inflammatory blood cells & $\approx$ & $\approx$ & $\uparrow$ & $\approx$ \\
Red blood cells - platelets & $\downarrow$ & $\approx$ & $\uparrow$ & $\uparrow$ \\
Coagulation & $\uparrow \uparrow$ & $\uparrow$ & $\uparrow$ & $\approx \uparrow$ \\
Vascular inflammation & $\approx$ & $\approx$ & $\approx$ & $\approx$
\end{tabular}

The genotype effects represent the effects induced by both NPs in the Bmal1 -/mice as compared to those of the Bmal1 +/+ mice; the time effects represent the effects induced by both NPs at T2 as compared to T1, without a distinction between both genotypes. $\uparrow \uparrow$ represents a significant increase $(p<0.01)$ compared to its proper respectively control group; $\uparrow$ increase $(p<0.05)$; $\downarrow \downarrow$ decrease $(p<0.01) ; \downarrow$ decrease $(p<0.05) ; \approx$ no significant change.

blood neutrophils, lymphocytes and eosinophils followed the same pattern (data not shown).

Overall, MWCNT decreased the number of red blood cells $(\mathrm{RBC})$ in the blood $(73.2 \%$ of the control), only in the $\mathrm{Bmal1}^{+/+}$mice (Figure 4A). The numbers were higher at $\mathrm{T} 2$ than at $\mathrm{T} 1$ and the $\mathrm{Bmal1}^{-/-}$mice had higher values than the Bmal1 $1^{+/+}$mice. Effects of dose, genotype and timepoint were not additive, as indicated by a three-way interaction effect $(p=0.035)$. ZnO NPs did not affect the RBC levels (Figure 4G), however the observations regarding time $(\mathrm{p}=0.0002)$ and genotype $(\mathrm{p}=0.029)$ were similar.

The Mean Corpuscular Volume (MCV) was however not affected by the MWCNT exposure, meaning that the hemolytic response was not accompanied by a de novo $\mathrm{RBC}$ production. The MCV was lowest in the Bmal1 ${ }^{-1-}$ animals at T2 (time $\mathrm{x}$ genotype interaction: $\mathrm{p}=0.017$ for MWCNTs and $\mathrm{p}=0.044$ for ZNO NPs).

The number of platelets was not significantly affected by the administration of either NP (Figure $4 \mathrm{~B}$ and $4 \mathrm{H}$ ), however the mice at $\mathrm{T} 2$ had significantly higher platelet levels than the mice at T1 $(\mathrm{p}<0.0001$ for MWCNT and $\mathrm{p}=0.0008$ for $\mathrm{ZnO}$ ) and the Bmal1 ${ }^{-/-}$mice also had more platelets (T1: $149.3 \%$ of the control, T2: 143.6\%) than the $\mathrm{Bmal1}^{+/+}$mice $(\mathrm{p}<0.0001$ for both NPs). The Mean Platelet Volume (MPV) correlated to the number of platelets where this parameter was higher at T1 than at $\mathrm{T} 2$ and also higher in the $\mathrm{Bmal1}{ }^{+/+}$mice than the Bmal1 ${ }^{-1-}$ mice. A summary of the data can be found in Table 1.

\section{Hemostasis parameters}

MWCNT administration decreased the PT (T1: 91.4\% of the control, T2: $89.9 \%$ for $\mathrm{Bmal1}^{+/+}$mice, T1: $95.3 \%$, T2: 91.3\% for Bmal1 $1^{-1-}$ mice; $\mathrm{p}=0.021$ ), without a difference between both doses (Figure 4C). Also, the Bmal1 ${ }^{-1-}$ mice had lower values than the Bmal1 ${ }^{+/+}$mice (T1: $82.5 \%$, T2: $88.2 \%$; for both NPs $\mathrm{p}<0.0001)$. The fibrinogen
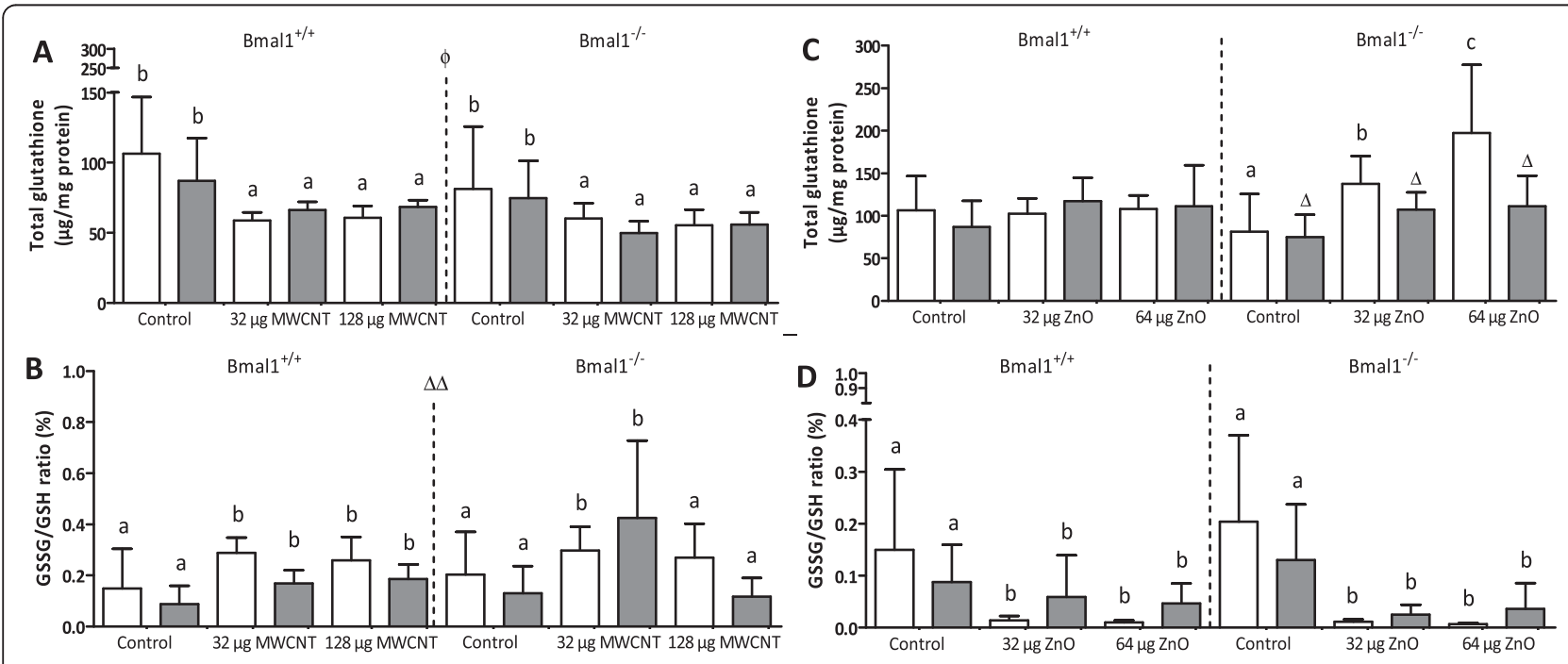

Figure 3 Total glutathione and ratio of oxidized versus reduced glutathione measured in lungs of Bmal1 ${ }^{+/+}$and Bmal $1^{-/-}$mice, 24 hours (T1) and 8 weeks (T2) after the last exposure to MWCNTs or ZnO NPs. Total glutathione (A, C) and the GSSG/GSH ratio (B, D) were measured in lung homogenates of each mouse. White bars depict measurements at T1, grey bars depict measurements at T2. A different letter indicates a significant effect of this group compared to the control of the same time point, within the same genotype. $\Delta p<0.05$ compared to the same experimental group of T1. $\Delta \Delta \mathrm{p}<0.01$ compared to the same experimental group of T1. Genotype-effects are indicated by $\Phi$. $\Phi p<0.05$ between $\mathrm{Bmal}^{+/+}$and Bmal1 ${ }^{-/-}$mice. When a symbol is placed in the middle of the figure, the time $(\Delta)$ and genotype-effects $(\Phi)$ are observed in all experimental groups. 


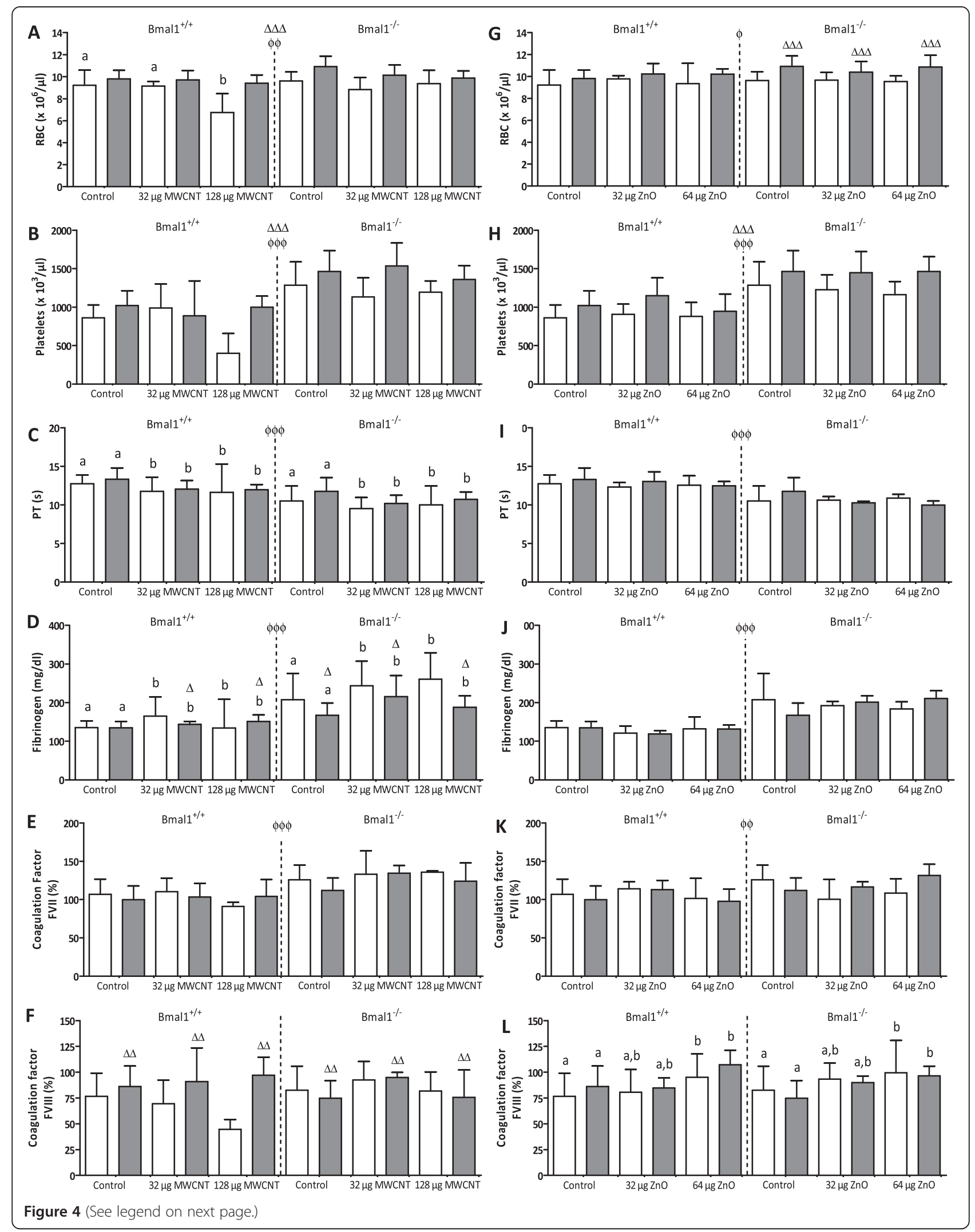


(See figure on previous page.)

Figure 4 Extra-pulmonary endpoints measured in Bmal1 ${ }^{+/+}$and Bmal1 $1^{-/-}$mice, 24 hours (T1) and 8 weeks (T2) after the last exposure to MWCNTs or ZnO NPs. Total amount of red blood cells, (RBC) (A, G), total amount of platelets $(\mathbf{B}, \mathbf{H})$ measured in diluted whole blood of all mice. PT (C, I), fibrinogen concentrations $(\mathbf{D}, \mathbf{J})$, coagulation factor VII $(\mathbf{E}, \mathbf{K})$ and $\mathbf{V I I I}(\mathbf{F}, \mathbf{L})$ measured in plasma of each mouse. White bars depict measurements at T1, grey bars depict measurements at T2. $\Delta p<0.05$ compared to the same experimental group of $\mathrm{T} 1 . \Delta \Delta \mathrm{p}<0.01$ compared to the same experimental group of T1. $\Delta \Delta \Delta \mathrm{p}<0.001$ compared to the same experimental group of T1. $\Phi \mathrm{p}<0.05$ between Bmal $1^{+/+}$and Bmal1 $1^{-/-}$

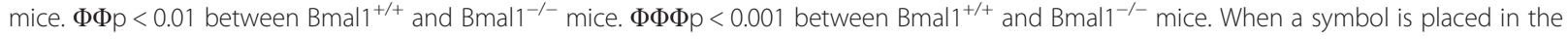
middle of the figure, the time $(\Delta)$ and genotype-effects $(\Phi)$ are observed in all experimental groups.

concentrations were increased in the $\mathrm{Bmal1}^{-/-}$mice exposed to the MWCNTs (125.5\% of the control $\mathrm{p}=0.036$ ), but not to the ZnO NPs (Figure 4D). Overall, the Bmal1 ${ }^{-/-}$ mice had higher fibrinogen concentrations than the Bmal $1^{+/+}$mice $(153.1 \%$ of the control, $\mathrm{p}<0.0001)$ and after MWCNT exposure the level at T1 was higher than at $\mathrm{T} 2$ (time $\mathrm{x}$ genotype interaction: $\mathrm{p}=0.029$ ) (Figures 4D and $4 \mathrm{~J})$.

Both NPs did not have an effect on the concentrations of coagulation factor FVII, however the $\mathrm{Bmal1}^{-/-}$mice had higher values of this coagulation factor than the Bmal1 ${ }^{+/+}$mice $(117.8 \%$; $\mathrm{p}<0.0001$ for the MWCNTs and $\mathrm{p}=0.009$ for ZnO NPs). The coagulation factor FVIII was not affected by MWCNT administration. The ZnO NPs increased FVIII (T1: 123.9\%, T2: 124.4\% for $\mathrm{Bmal1}^{+/+}$ mice, T1: $120.3 \%$, T2: $128.9 \%$ for $\mathrm{Bmal1}^{-/-}$mice; $\mathrm{p}=$ 0.001 ) in both genotypes and at both time points.

In a PCA involving PT, fibrinogen, FVII and FVIII, the first PC was positively correlated with the fibrinogen concentration and coagulation factors FVII and FVIII and negatively correlated with PT, so these parameters are a good measure for coagulation. For the MWCNTs the first PC accounted for $60 \%$ of the variability and $55 \%$ for the $\mathrm{ZnO}$ NPs. For MWCNT administration, this first PC showed a significant dose effect (higher values for both doses than in the control group, $\mathrm{p}=0.006$ ), higher values at $\mathrm{T} 1$ than $\mathrm{T} 2(\mathrm{p}=0.03)$ and higher values in the Bmal1 $^{-/-}$mice than in the WT $(\mathrm{p}<0.001)$, which is in line with the results for PT and fibrinogen separately. For $\mathrm{ZnO} \mathrm{NP}$ administration, there was only a difference for genotype (higher values in $\mathrm{Bmal1}^{-/}$mice, $\mathrm{p}=<0.001$ ), which again confirmed the results for PT, fibrinogen and FVII. A summary of the data can be found in Table 1.

\section{Aorta histology}

The proximal section of the aorta (aortic arch) was dissected and vertical sections were made, perpendicular to the surface of the tissue. The sections were stained for F4/ 80 , a macrophage antigen, in order to assess early vascular inflammation. There were no significant differences in F4/ 80 staining between the different groups (data not shown).

\section{Correlations}

When considering all pulmonary endpoints measured, we could observe a strong positive correlation between the BAL neutrophils and both cytokine concentrations: IL-1 $\beta$ (Pearson correlation coefficient (PCC): 0.696, $\mathrm{p}=$ 0.0007 ) and KC (PCC: 0.671, $\mathrm{P}=0.0012)$, in the $\mathrm{Bmal1}^{+/+}$ mice exposed to $\mathrm{ZnO}$ NPs. These correlations were not present in the $\mathrm{Bmal1}^{-/-}$mice, however, the IL-1 $\beta$ concentrations and total glutathione (PCC: 0.512, $\mathrm{p}=0.0297$ ) were correlated. For the MWCNT-exposed mice, there were only correlations between both cytokines in both genotypes in the $\mathrm{Bmal1}^{+/+}$mice and in the $\mathrm{Bmal1}^{-/-}$mice, the BAL neutrophils were correlated with both cytokines: IL-1 $\beta$ (PCC: 0.633, p=0.0201) and KC (PCC: 0.665, p = 0.01232 ) (data not shown).

When considering all toxicological endpoints measured, we could also observe correlations between pulmonary inflammation, oxidative stress and the hemostasis parameters. In the Bmal1 ${ }^{+/+}$mice exposed to MWCNTs, the BAL neutrophils were positively correlated with fibrinogen concentrations in the blood (PCC: 0.644, $\mathrm{p}=0.0095$ ) and in the $\mathrm{Bmal1}^{-/-}$mice, the IL- $1 \beta$ concentrations were positively correlated with fibrinogen concentrations (PCC: 0.620, $\mathrm{p}=0.0179$ ). In the $\mathrm{Bmal1}^{+/+}$mice exposed to $\mathrm{ZnO}$ NPs, the total BAL cells were positively correlated with fibrinogen (PCC: 0.572, $\mathrm{p}=0.0105$ ).

An additional analysis was performed where all mice of the same genotype were pooled, independent of the nanomaterial they were exposed to (see Table 2). In the Bmal1 ${ }^{+/+}$mice, a positive correlation was found between the BAL neutrophils and fibrinogen concentrations (PCC: 0.584, $\mathrm{p}=0.0003$ ) and negative correlations were found between the PT and BAL neutrophils (PCC: $-0.380, \mathrm{p}=$ $0.0265)$, IL-1 $\beta$ concentration (PCC: $-0.483, p=0.0053$ ) and $\mathrm{KC}$ concentrations (PCC: $-0.426, \mathrm{p}=0.015$ ). In the $\mathrm{Bmal1}^{-/-}$mice, the fibrinogen concentrations were correlated with the IL-1 $\beta$ concentrations (PCC: $0.656, \mathrm{p}<0.0001$ ), KC concentrations (PCC: $0.538, \mathrm{p}=0.0018$ ) and GSSG/GSH ratio (PCC: $0.412, \mathrm{p}=0.019$ ). The $\mathrm{PT}$ is negatively correlated with $\mathrm{KC}$ concentrations (PCC: $-0.413, \mathrm{p}=0.0208$ ).

\section{Discussion}

In this study we assessed the pulmonary and extrapulmonary toxicity of MWCNTs and ZnO NPs after repeated pulmonary administrations. To our knowledge, this is the first study where Bmal1 ${ }^{-/-}$mice are used to study NP pulmonary toxicity and the effect on coagulation after pulmonary NP exposure. 
Table 2 Pearson correlation coefficiants between the pulmonary and cardiovascular endpoints measured

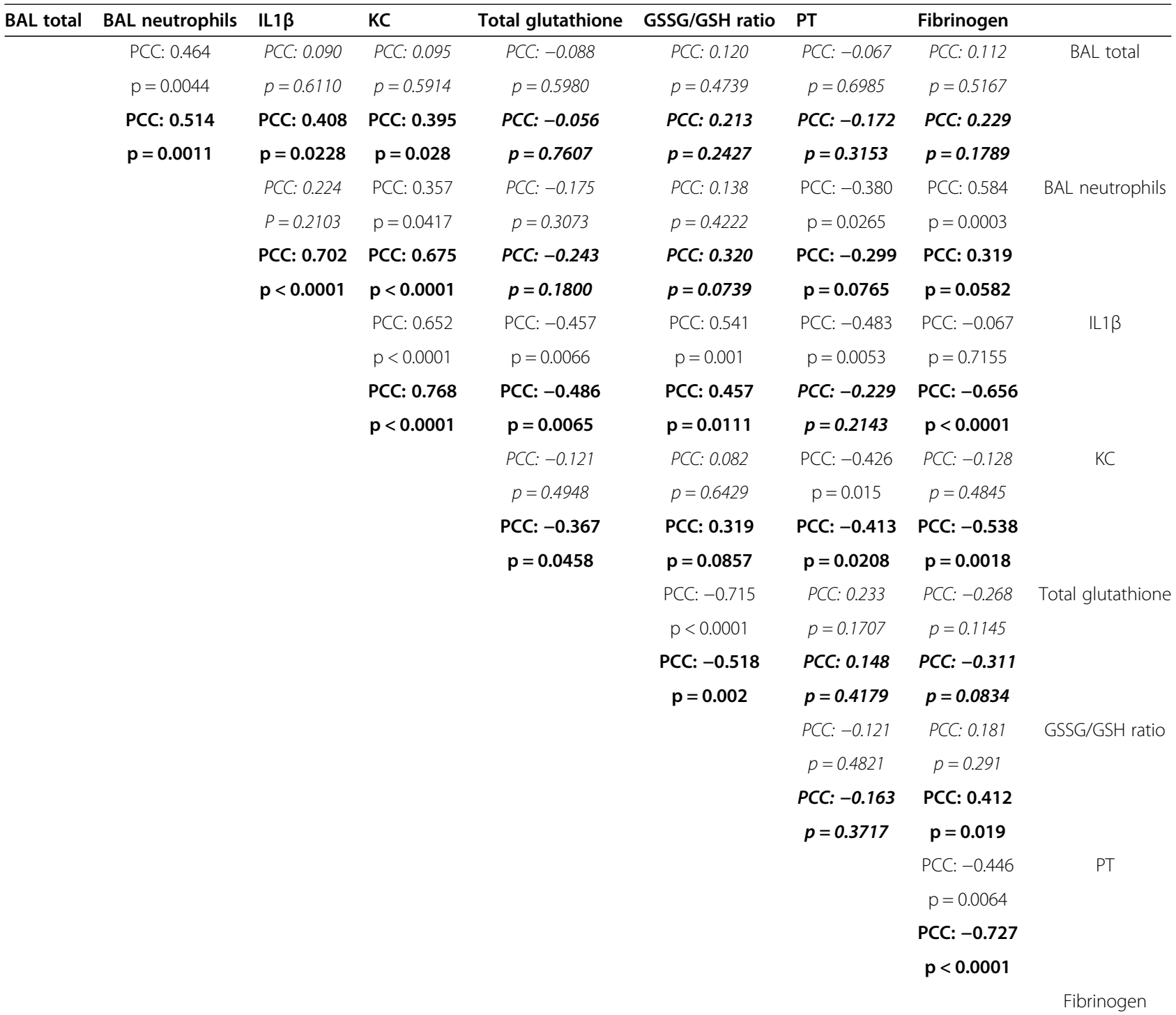

Pearson correlation coefficients (PCC) with concomitant $\mathrm{p}$-values are presented for the measured endpoints. A comparison was made between the NP-exposed mice and the controls where the results of both NPs were pooled. The plain values represent the results from the Bmal $1^{+/+}$mice and the bold values represent the results from the Bmal1 $1^{-1-}$ mice. The values in italic are non-significant correlations where a p-value of 0.05 was considered to be significant. No correlations were found for RBC and platelet counts, FVII and FVIII.

\section{Nanoparticle-induced pulmonary effects}

Considering the pulmonary endpoints measured, the two NPs evoked different responses; MWCNTs induced a pronounced pulmonary inflammatory response with increased BAL cells, secretion of IL-1 $\beta$ and $\mathrm{KC}$ and a clear induction of oxidative stress; in contrast, the $\mathrm{ZnO}$ NPs induced a different pattern of effects in the lungs, i.e. a limited cellular influx in the lung and an increased total glutathione content. The findings after MWCNTs administration are not surprising; it was shown in earlier studies that carbon nanotubes (CNTs) cause pulmonary inflammation (with granuloma formation) which can persist up to 1 month after the administration [26,27]. Here, the number of BAL cells, together with the measured cytokines, decreased over the 8 weeks after the last administration, however they were still elevated compared to the control. This is probably caused by the incomplete clearance of MWCNT which was apparent from the presence of MWCNT loaded (black) macrophages in the BAL at T2 (see Figure 2). The BAL macrophages of $\mathrm{ZnO}$ NPexposed animals did not show internalized NPs, possibly because these NPs are less electron dense than MWCNTs and/or the ZnO NPs can solubilize within the time window of the experiment.

In acute inhalation studies, in general, $\mathrm{ZnO}$ NPs show a transient acute pulmonary inflammatory response [28,29]. 
A recent study also showed pulmonary inflammation after a single acute exposure (inhalation of $0.86 \mathrm{mg} / \mathrm{m}^{3}$ during 5 hours), but after inhalation of $\mathrm{ZnO}$ NPs at the same dose during 5 consecutive days no inflammation was found [30]. This is comparable to observations in humans after pulmonary exposure to high doses of zinc and/or zinc oxides. A syndrome known as metal fume fever (MFF) is an acute inflammatory response which resolves 1-4 days after exposure [31]. However, there are some discrepancies with regard to the dose of which MFF is triggered. Several studies reported symptoms after exposure ranging from $77 \mathrm{mg}$ zinc $/ \mathrm{m}^{3}$ (15-30 minutes) to $600 \mathrm{mg} \mathrm{zinc} / \mathrm{m}^{3}$ (1012 minutes), whereas concentrations slightly higher than the permissible exposure limit $\left(5 \mathrm{mg} / \mathrm{m}^{3}\right)$ during several hours did not elicit MFF-like symptoms [32].

The subacute exposure of ZnO NPs in this study only led to a very mild (and non-significant) total BAL cell increase $24 \mathrm{~h}$ after the last administration, which decreases at T2. The differences with the aforementioned studies are the method of exposure (inhalation vs. oropharyngeal aspiration) and therefore, the doses cannot easily be compared. In the current study, we chose to administer multiple times a low dose (6.4 or $12.8 \mu \mathrm{g}$ /instillation) thus avoiding local epithelial damage in the lung and acute toxicity. This procedure might explain the lack of a significant inflammatory response, as in the study by Chen et al. [30]. Considering only the BAL neutrophils in the $\mathrm{Bmal1}^{+/+}$mice, our data are in accordance with other reports, although a decrease in neutrophils was observed in the Bmal1 ${ }^{-1-}$ mice, accompanied by a significant decrease of pulmonary cytokines and a significant increase in total glutathione.

Moreover, a zinc excess is known to suppress immunity. In humans, plasma-zinc occurs in a concentration of only $12-16 \mu \mathrm{mol} / \mathrm{L}$ but a deficiency as well as an excess cause decreased function of several immune cells [33,34]. Zinc excess causes macrophage activation, directs the chemotactic activity of neutrophils and suppression of NK cell functions. Also, T cell functions are suppressed and B cells undergo apoptosis [34]. We presume that our doses are at the border of toxicity explaining the absence of pulmonary inflammation and the suppression of cytokine release. We also cannot distinguish between effects caused by dissolved or particulate $\mathrm{Zn}$. Preliminary dissolution studies showed a pronounced dissolution in water and a somewhat lower dissolution in medium [35]. The dispersion medium (sterile water) used in this study contained 2 vol\% serum which can possibly reduce the dissolution (compared to water) during the preparation of the samples. Taking into account the large volume for dissolution of $\mathrm{Zn}$ in a vivo system it can be assumed that the $\mathrm{ZnO}$ NPs dosed will finally solubilize fully.

Possibly, the responsiveness of the immune system in the $\mathrm{Bmal1}^{-/-}$mice differed from that of the $\mathrm{Bmal1}^{+/+}$ mice. Bmal1 has anti-inflammatory effects since it reduced Ccl2 transcription and attenuated Ly6Chi monocyte numbers and inflammation at an inflamed site [36,37]. Inflammatory diseases (asthma, rheumatoid arthritis, atherosclerosis) are known to have strong circadian components with exacerbations at night or during the early morning. Moreover, several experimental studies showed a worse disease outcome or higher mortality when wild-type mice were housed in constant darkness than at the normal light/dark cycles [37]. So, given these results, one would expect an increased inflammatory response in $\mathrm{Bmal1}^{-/-}$ mice, however, we found a similar vascular macrophage influx in both genotypes for the MWCNTs. Moreover, Hemmeryckx et al. showed an absence of vascular inflammatory response in the mesenteric blood vessels of $\mathrm{Bmal1}^{-/-}$mice despite the high numbers of circulating leukocytes, suggesting these cells are less reactive [19].

\section{Nanoparticle-induced hemostasis effects}

The pulmonary administration of the NPs caused hemostatic toxicity, in addition to the observed pulmonary effects. The MWCNTs showed a remarkable anemic effect with significantly decreased RBCs and non-significantly decreased platelets at the cumulative dose of $128 \mu \mathrm{g}$. However, these observations were absent in the $\mathrm{Bmal1}^{-1-}$ mice. Most research regarding hemolysis has been performed on human or animal whole blood with direct contact with the RBCs [38,39]. However, one study has shown the hemolytic effect of acid functionalized SWCNTs after intratracheal instillation in Swiss mice [40]. The effect was transient with RBC counts returning to semi-normal levels after 72 hours. As an explanation for this anemic response, the authors suggested the possibility of SWCNTs to rapidly diffuse through the thin alveolar membrane. However, we doubt that the anemic response is a direct effect since it has been shown that CNTs are cleared very poorly from the lungs and thus only a very small portion of the administered dose might eventually reach the blood stream. Elgrabli et al. observed the retention of $37 \%$ of the administered dose, 3 months after a single instillation of $100 \mu \mathrm{g}$ CNTs in a rat lung [41]. Muller et al. observed the retention of $81.2 \%$ of the administered dose, 60 days after the instillation of $0.5 \mathrm{mg} / \mathrm{rat}$ [42].

A possible explanation for this acute anemic response is the state of "anemia of inflammation" which is an immune disorder that has been reported in numerous diseases with an inflammatory component [43]. As an example, in chronic obstructive pulmonary disease (COPD) an incidence of anemia has been reported ranging from $5-33 \%$, with highest incidences during acute exacerbations [44-46]. It is believed that inflammatory cytokines interfere with normal erythropoiesis in a complex process where the dysregulation in iron homeostasis and erythropoietin production, impaired proliferation 
of erythroid progenitor cells and a reduced life span of RBCs are involved [47]. Here, the observed anemic effect is acute and resolves at T2, which coincides with the decreased pulmonary inflammation at T2.

The subacute administration of both NPs also caused a procoagulant effect with the MWCNTs causing a significantly shorter PT and increased fibrinogen concentrations while $\mathrm{ZnO}$ NPs exposure significantly increased the amount of coagulation factor VIII. Local inflammation can induce an acute phase response which is a nonspecific systemic reaction with neurological, endocrine and metabolic alterations [48]. As a consequence, several plasma proteins are induced e.g. C-reactive protein, cytokines and coagulation factors. Fibrinogen and FVIII are both acute phase proteins, associated with cardiovascular disease $[49,50]$. The hemostatic effects induced by MWCNTs can be explained by this reaction; however, the $\mathrm{ZnO}$ NPs did not cause an inflammatory response suggesting that both NPs affect hemostasis by different mechanisms. Possibly, other factors e.g. oxidized lipids and proteins can be involved activating the acute phase response and/or neurohumoral signaling, resulting in an altered cardiovascular function. It is possible that none of these mediators individually stimulate the extrapulmonary responses but together orchestrate this response [51]. Moreover, the Pearson's correlations analysis indicated a correlation between the fibrinogen concentrations on the one hand and BAL neutrophils and IL- $1 \beta$ concentrations in the lungs on the other hand, for the MWCNT-exposed mice. This is suggestive for a causal relation between the pulmonary inflammation with the observed prothrombotic effects.

The hemostatic effects were more pronounced in the $\mathrm{Bmal1}^{-/-}$mice, but also present in the Bmal1 ${ }^{+/+}$mice. Previous studies reported a prothrombotic effect after acute pulmonary administration of NPs. Jun et al. observed enhanced venous thrombus formation and platelet aggregation after the intratracheal instillation of 5-10 mg/ $\mathrm{kg}$ bw silver NPs in rats [52]. Starting from a concentration of $50 \mu \mathrm{g}$ diesel exhaust particles (DEPs), Nemmar et al. observed acute increased thrombosis formation in the right femoral vein and artery in hamsters [53]. On the contrary, Zhu et al. reported an increased PT and aPTT compared to the control, 30 days after intratracheal instillation of $0.8 \mathrm{mg} / \mathrm{kg}$ bw ferric oxide NPs in rats [54]. Yoshida et al. also reported an increased aPTT and marginally increased PT after the intranasal administration of $0.5 \mathrm{mg} 30 \mathrm{~nm}$ and $70 \mathrm{~nm} \mathrm{SiO}_{2}$ NPs during 7 days [55]. However, these doses are very high compared to the doses used in our study and are not representative for human exposure.

Nemmar et al. has indicated the importance of crosstalk between the pulmonary and systemic compartment in a study where the neutrophil enzyme elastase, secreted by pulmonary neutrophils, was responsible for the peripheral thrombotic effect observed in a hamster model [56]. Neutrophil elastase has been shown to promote the fibrinogen binding activity of the platelet integrin $\alpha \operatorname{IIb} \beta 3$ by cleaving the $\alpha \mathrm{IIb}$ subunit. This cleavage potentiates platelet aggregation induced by low concentrations of cathepsin $\mathrm{G}$, another neutrophil protease $[57,58]$.

\section{Genotype-related effects}

Along the NP-induced effects, there were also significant differences in the blood parameters between both genotypes. The Bmal1 ${ }^{-1-}$ mice exhibit higher amounts of WBCs, RBCs and platelets, and showed a prothrombotic phenotype as evidenced by shorter PT and increased fibrinogen and coagulation FVII concentrations. These results confirm earlier reports $[17,19]$. Moreover, the correlations between the pulmonary endpoints (inflammation and oxidative stress) and hemostasis parameters were more pronounced in the $\mathrm{Bmall}^{-/-}$mice, than in the $\mathrm{Bmal1}^{+/+}$mice, suggesting that the $\mathrm{Bmall}^{-/-}$are more sensitive to nanomaterial-induced effects, confirming our hypothesis.

A potential explanation for this prothrombotic phenotype is the deregulation of e.g. PAI-1, the most important regulator of fibrinolysis. PAI-1 is subject to diurnal variation, but in the $\mathrm{Bmal1}^{-/-}$mice these levels are continuously elevated resulting in an imbalance between fibrinolysis and its inhibition [17]. On the contrary, Hemmeryckx et al. observed decreased PAI-1 gene expression in subcutaneous and gonadal adipose tissue [59]. Also vWF is regulated by the circadian transcription complex and Bmal1 ${ }^{-/-}$mice have increased vWF plasma levels, contributing to the prothrombotic phenotype in these mice.

\section{Time-related effects}

We also observed several "time-effects": the pulmonary parameters decreased over time whereas the RBCs, platelets and coagulation increased over time. The fact that the measured pulmonary endpoints were decreased at T2 compared to T1 is not surprising. The observed inflammatory and (anti-)oxidative responses attenuated over the 8 weeks after the last exposure which is indicative of a healing process. The changes observed regarding RBCs and platelets are quite similar compared to the findings of Hemmeryckx et al., however our RBC levels are higher and platelet levels are lower as compared to theirs [19]. They also reported in $\mathrm{Bmal1}^{-/-}$mice a significantly decreased PT with age, significantly increased FVII and trends towards increased coagulation factor VIII and fibrinogen concentrations. Our results were less pronounced and not consistent in all experimental groups. This can probably be explained by the fact that our mice at T2 were 10 weeks younger than the mice 
used in the study of Hemmeryckx et al. and therefore the prothrombotic effects due to ageing could not yet be detected.

Lately, a lot of research focused on the progression of atherosclerosis following pulmonary NP exposure. The first step in the process of atherosclerosis is endothelial activation with an upregulation of adhesion molecules followed by the recruitment of macrophages to the vascular wall [60]. We therefore stained sections of the aorta for macrophages (F4/80 antigen) to assess whether the NPs used in this study could initiate this process of early atherogenesis. At the time points measured, we could not detect any differences in macrophage staining between the different experimental groups. However, $\mathrm{Cao}$ et al. observed increased plaque formation in $\mathrm{ApoE}^{-/-}$ mice (24 hours after the last instillation), using the same MWCNTs and the same dose $(25.6 \mu \mathrm{g} /$ instillation $)$ in the same dosing scheme [12]. In the BMAL1 ${ }^{-/-}$model, exposure to MWCNT affected in a similar way the pulmonary inflammation and oxidative stress: an increased neutrophilic inflammation which was persistent up to 28 days after the last administration, increased IL-1 $\beta, \mathrm{KC}$ and 8isoprostane formation in the lung. The systemic effect observed in the $\mathrm{BMAL1}^{-/-}$model differed significantly from that in $\mathrm{ApoE}^{-/-}$, indicating that presumably the Bmal1 ${ }^{-/-}$ mice are less prone to the development of atherosclerosis compared to the dyslipidemic $\mathrm{ApE}^{-/-}$mice.

\section{Conclusions}

In a prothrombotic mouse model, $\mathrm{Bmal1}^{-/-}$mice, we studied the pulmonary and hemostatic toxicity after a subacute exposure to MWCNTs and ZnO NPs. The MWCNTs induced a potent pulmonary inflammatory response, induced hemolysis and were procoagulant, shown by a reduced PT and increased fibrinogen concentrations. The $\mathrm{ZnO}$ NPs somewhat suppressed the pulmonary inflammatory response but significantly increased coagulation factor VIII. The procoagulant effects and correlations between the pulmonary and hemostatic endpoint were more pronounced in the $\mathrm{Bmal1}^{-/-}$mice than the Bmal1 $1^{+/+}$mice. This study supports evidence that the population with cardiovascular risk factors have higher risks for the development of hemostatic toxicity after pulmonary NP exposure. However, on the basis of our data possibly also people with a disturbed circadian rhythm, such as shift workers, could have a higher risk of developing particle-related heart disease.

\section{Methods}

\section{Animal model}

Breeding couples of mice heterozygous for Bmal1 (100\% C57BL/6 J) were kindly provided by Dr K. Esser (University of Kentucky, Lexington, KY). Female Bmal1 ${ }^{-/-}$mice and $B$ mal1 $1^{+/+}$littermates were generated in the animal facility of the KU Leuven and genotyped as described by Bunger et al. [61].

All animals were kept in micro-isolation cages in a temperature- and light-controlled (12-hour night/day cycle) environment and had free access to drinking water and standard chow ad libitum. All animal procedures were approved by the Ethical Committee for animal experiments of the KU Leuven and performed in accordance with the National Institutes of Health Guide for the Care and Use of Laboratory Animals (1996).

\section{Nanomaterials and preparation of exposure suspensions}

The MWCNTs (Arkema Graphistrength C100; NM402) and $\mathrm{ZnO}$ NPs were (BASF Z-Cote; zinkite, uncoated, primary size: $100 \mathrm{~nm}$, NM110) were obtained from the European Commission Joint Research Centre Nanomaterials Repository (http://ihcp.jrc.ec.europa.eu/our_ activities/nanotechnology/nanomaterials-repository). Detailed physico-chemical characterization was performed by Kermanizadeh et al. [62]. The X-ray diffraction (XRD) size for the ZnO NPs ranged between 70 to $>100 \mathrm{~nm}$. As determined by transmission electron microscopy (TEM), the MWCNTs had a diameter of 6-20 nm and length of $700-4000 \mathrm{~nm}$ and the size of the ZnO NPs ranged between 20-250/50-350 nm. The Brunauer-Emmett-Teller (BET) surface area was 225 and $14 \mathrm{~m}^{2} / \mathrm{g}$ for MWCNTs and $\mathrm{ZnO}$ NPs respectively [62].

The dissolution of $\mathrm{Zn}+$ ions from the $\mathrm{ZnO}$ NP dispersions was determined within the framework of the ENPRA (engineered nanoparticle risk assessment) project. These measurements were performed at a slightly different concentration $(0.32 \mathrm{mg} / \mathrm{ml})$ than the concentrations used in this study, namely $0.25 \mathrm{mg} / \mathrm{ml}(6.4 \mu \mathrm{g} /$ aspiration) and $0.51 \mathrm{mg} / \mathrm{ml}(12.8 \mu \mathrm{g} /$ aspiration $)$. At a concentration of $0.32 \mathrm{mg} / \mathrm{ml}$, the amount of $\mathrm{Zn}+$ ions measured in DMEM medium $(+10 \%$ FBS $+1 \%$ PenStrep) and water after 24 hours were 23.76 and 54.01 ppm respectively. The estimated solubility limits were determined as 29.6 and $67.2 \mu \mathrm{g} \mathrm{Zn} / \mathrm{ml}$ in medium and water respectively [35]. In our experiments, dissolution of $\mathrm{Zn}$ is expected to be higher than $20 \mu \mathrm{g} / \mathrm{ml}$, in both dose concentration, at the time of exposure. The dissolution kinetics of $\mathrm{ZnO}$ in the lung has not been assessed.

The NPs were weighed and dispersed in sterile water containing 2 vol\% mouse serum (dispersion medium) to create a stock concentration of $2.56 \mathrm{mg} / \mathrm{ml}$. Mouse serum was obtained from full blood from Bmal1 $1^{+/-}$mice. Blood, taken from the inferior vena cava, was collected in Minicollect serum tubes, left at room temperature for 30 minutes and centrifuged at $2000 \mathrm{~g}$ for 10 minutes. The serum was collected and tested to be free of LPS (LAL assay).

The NP stock suspensions were sonicated using a Microson $^{\mathrm{Tm}}$ ultrasonic cell disruptor (Misonix, Newtown, 
USA), equipped with a $1 / 8$ " disruptor horn for $16 \mathrm{mi}$ nutes on ice/water. Thereafter, the stock concentrations were diluted to obtain the final concentrations for exposure: 160 and $640 \mu \mathrm{g} / \mathrm{ml} \mathrm{MWCNT} \mathrm{(corresponding} \mathrm{to}$ 6.4 and $25.6 \mu \mathrm{g} /$ dosing) and 256 and $512 \mu \mathrm{g} / \mathrm{ml} \mathrm{ZnO}$ (corresponding to 6.4 and $12.8 \mu \mathrm{g} / \mathrm{dosing}$ ). Based on preliminary studies, we chose to lower the dose of $\mathrm{ZnO}$ NPs exposure since the pulmonary administration of $25 \mu \mathrm{g} \mathrm{ZnO}$ NPs induced an acute mortality, whereas a dose of $12.5 \mu \mathrm{g}$ did not [63].

The NP suspensions were used within one hour after sonication.

\section{Study design (Experimental lay-out)}

$\mathrm{Bmal1}^{-/-}$and $\mathrm{Bmal1} 1^{+/+}$mice were dosed (under light anesthesia with isoflurane) via oropharyngeal aspiration once a week, during 5 consecutive weeks. The first dose was administered at the age of 8 weeks. For the MWCNT, the Bmal1 mice were either dosed 6.4 $\mu$ g per aspiration (total amount administered of $32 \mu \mathrm{g}$ ) or $25.6 \mu \mathrm{g}$ per aspiration (total of $128 \mu \mathrm{g}$ ). For the $\mathrm{ZnO}$ NPs, mice were either dosed $6.4 \mu \mathrm{g}$ or $12.8 \mu \mathrm{g}$ per aspiration (for a total of $32 \mu \mathrm{g}$ or $64 \mu \mathrm{g}$ respectively). Each administration consisted of a volume of $25 \mu \mathrm{l}$. The control animals received the dispersion medium. Mice were sacrificed either, 24 hours after the last administration (T1, age of 12 weeks) or 8 weeks after the last administration (T2, age of 20 weeks).

The mice were sacrificed using an intraperitoneal overdose of pentobarbital. Blood was immediately taken via the retro-orbital plexus and collected in a tube containing citrate. The end concentration of citrate in the blood was $0.38 \%$. A broncho-alveolar lavage (BAL) was performed, consisting of two flushes of $1 \mathrm{ml} / 25 \mathrm{~g}$ body weight. The aortic arc/bow was taken and used for histology (kept at $4 \%$ formaldehyde). Finally, the lung-heart block was taken and the superior lobe of the right lung and the heart were kept on $4 \%$ formaldehyde for histology. The left lung was snap-frozen for GSSG/GSH measurements. The remaining lobes of the right lung were also snap-frozen and kept for cytokine measurements.

\section{Blood samples}

Immediately after the withdrawal, a small portion of the blood was diluted 5-fold (in saline) to perform cell counts using the Cell-Dyn ${ }^{\odot} 3200 \mathrm{R}$ counter (Abbott Diagnostics, Louvain-la-Neuve, Belgium). The remaining part of the blood was immediately centrifuged twice at $16100 \mathrm{~g}$, for 10 minutes at room temperature. The plasma was stored at $-80^{\circ} \mathrm{C}$ for measurements of the partial thromboplastin time (aPTT), the prothrombin time (PT) and plasma levels of coagulation factors (F) VII, FVIII and fibrinogen using the BCS-XP automated coagulation analyzer (Siemens, Beerzel, Belgium).

\section{Broncho-alveolar lavage}

The pooled BAL fluid was centrifuged at $400 \mathrm{~g}$, for 10 minutes at $4^{\circ} \mathrm{C}$. The supernatant was stored at $-80^{\circ} \mathrm{C}$. The cell pellet was resuspended and a total cell count was performed using a Bürker cell counter. Cells were spun on microscope slides at $300 \mathrm{~g}$ for 6 minutes (Cytospin 3, Shandon, TechGen, Zellik, Belgium) and stained using the DiffQuick ${ }^{\circledR}$ method (Medical Diagnostics, Düdingen, Germany). For each sample, the number of macrophages, neutrophils, eosinophils and lymphocytes were counted.

\section{Cytokine release}

The lung tissue was homogenized in $0.5 \mathrm{ml}$ of $1 \%$ bovine serum albumin (BSA in HBSS-) and afterwards centrifuged at $16100 \mathrm{~g}, 4^{\circ} \mathrm{C}$ for 10 minutes. The supernatant was frozen at $-80^{\circ} \mathrm{C}$ until cytokine measurement using the MSD mouse pro-inflammatory 7-plex (IFN- $\gamma$, IL-1 $\beta$, IL-6, IL-10, IL-12p70, KC/GRO, TNF- $\alpha$ ) according to the manufacturer's instructions (Meso Scale Discovery, Gaithersburg, Maryland, USA).

\section{Glutathione determination}

The left lung was homogenized on ice in cold $40 \mathrm{mM} \mathrm{N}$ ethylmaleimide $(20 \mathrm{ml} / \mathrm{g}$ tissue, to prevent rapid oxidation of GSH) and then centrifuged at $14000 \mathrm{~g}$ for 15 minutes at $4^{\circ} \mathrm{C}$. The supernatant was transferred to a new tube and $5 \%$ metaphosphoric acid was added (1/5th of the supernatant volume, final concentration is $1 \%$ metaphosphoric acid, for removing the proteins), mixed and again centrifuged at $14000 \mathrm{x}$ g during 15 minutes at $4^{\circ} \mathrm{C}$. The supernatant was stored at $-80^{\circ} \mathrm{C}$ until measurements. The measurements of the reduced (GSH) and oxidized (glutathione disulfide, GSSG) forms of glutathione were performed by ultra-pressure liquid chromatography (UPLC), in combination with tandem mass spectrometry (MSMS). An in-house developed LC/MS-MS method was used, partially based on the method of Guan et al. as follows. The LC/MS-MS analysis was conducted on a Waters $^{\oplus}$ Acquity TM UPLC coupled to a Waters ${ }^{\oplus}$ Micromass MS Technologies Quattro Premier TM mass spectrometer using electro spray ionization (ESI). The LC separation was done on a Waters Acquity UPLC BEH C18, $50 \mathrm{~mm} \times 2.1 \mathrm{~mm}, 1.7 \mu \mathrm{m}$ column, held at a temperature of $40^{\circ} \mathrm{C}$. The mobile phase used for the $\mathrm{LC}$ separation was a mixture of $0.1 \%$ formic acid in water and $0.1 \%$ formic acid in acetonitrile. The flow rate was $0.35 \mathrm{ml} / \mathrm{min}$ and the total run time was 4 minutes. Ten $\mu \mathrm{l}$ aliquots were injected per sample. The analyses were performed in the ESI + mode and a multiple reaction monitoring (MRM) methodology was used with argon as the collision gas.

Data were normalized to protein content measured by the Bradford method using bovine serum albumin as the 
standard. The ratio of GSSG to total glutathione was then calculated.

\section{Histology}

The arc/bow of the aortic tissues was embedded in paraffin, dehydrated in ethanol (70\%-96\%-100\%) and cleared in xylene. Sections $(7 \mu \mathrm{m})$ were vertically cut (perpendicular to the surface of the tissue) using a HM360 microtome (Microm, Walldorf, Germany). Subsequently, they were deparaffinized in xylene, followed by decreasing series of ethanol concentrations and distilled water. The sections were stained for F4/80. To expose F4/80 antigens, the sections were treated with $10 \mathrm{mM} \mathrm{Na}_{3}$ citrate with $0.05 \%$ Tween during 40 minutes at $95^{\circ} \mathrm{C}$ and afterwards allowed to cool. The endogenous peroxidase activity was blocked by incubating the sections in methanol supplemented with $0.3 \% \mathrm{H}_{2} \mathrm{O}_{2}$ during 20 minutes at RT. Afterwards, the sections were incubated with TNB during 45 minutes and then the rat anti-mouse antibody (2 $\mu \mathrm{g} / \mathrm{ml}$, Serotec, Puchheim, Germany) was incubated overnight. The slides were incubated with the secondary antibody (rabbit anti rat Ig-biotin, DAKO) during 45 minutes and afterwards the signal was amplified using the biotinyl tyramide kit (1/50, NEL700001KT, Perkin Elmer Life Sciences, Zaventem, Belgium). F4/80 signals were visualized with 3,3'-Diaminobenzidine (DAB, Sigma-Aldrich, Diegem, Belgium).

\section{Statistical analysis}

The associations between each biological endpoint and treatment groups were studied for MWCNT and $\mathrm{ZnO}$ NPs separately. Data from one single control group were used for comparison with both MWCNT and ZnO NP administration. The experimental set-up with three different variables (i.e. genotype; concentration of NP administered: control, low, high; time of measurement after administration) and all possible combinations called for a three-way ANOVA model, allowing for three-way interactions and pairwise two-way interactions between the three explanatory variables. For each endpoint, we built a full model including main effects and all two-way and three-way interaction terms. Then, nonsignificant interaction terms or main effects $(p>0.05)$ were manually removed from the model in a stepwise procedure. Whenever interaction terms involving genotype showed statistical significance, subsequent subgroup analyses were performed for Bmal1 ${ }^{+/+}$and $\mathrm{Bmal1}^{-/-}$mice separately.

BAL cell type concentrations were highly positively intercorrelated, and so were WBC types. Therefore, in order to summarize all BAL cell or WBC types in one model (meanwhile reducing the risk of making a type I error), we performed a principal component analysis (PCA) of BAL cell types and WBC types, respectively.
The first component resulting from the PCA was interpreted as an overall indicator of BAL cells or WBC augmentation and analyzed in a three-way ANOVA model similar to the one-by-one analysis of BAL cell types and WBC types.

Associations among specific biological endpoints were further explored by Pearson's correlation analyses; initially for MWCNT and ZnO NP treatment separately and finally grouping the NP exposures per mouse phenotype.

Results are reported as the percentage of the control. Statistical analyses were performed using SAS software, version 9.3. (SAS Institute, Cary, NC, USA) and all tests were two-sided with $\alpha=0.05$.

\section{Abbreviations}

ApoE: Apo lipoprotein E; aPTT: Activated partial thromboplastin time; BAL: Broncho-alveolar lavage; BET: Brunauer-Emmett-Teller surface area; BH4: Tetrahydrobiopterin; Bmal1: Brain and muscle ARNT-like protein - 1; BSA: Bovine serum albumin; CNT: Carbon nanotube; COPD: Chronic obstructive pulmonary disease; DAB: 3,3'-diaminobenzidine; eNOS: Endothelial nitric oxide synthase; GSH: Reduced glutathione; GSSG: Oxidized glutathione;

IFN- $\gamma$ : Interferon gamma; IL: Interleukin; KC: Cytokine-induced neutrophil chemo-attractant; LC: Liquid chromatography; LPS: Lipopolysaccharide; MCV: Mean corpuscular volume; MFF: Metal fume fever; MPV: Mean platelet volume; MRM: Multiple reaction monitoring; MS-MS: Tandem mass spectrometry; MWCNT: Multi-walled carbon nanotubes; NAC: N-acetyl cysteine; NO: Nitric oxide; NP: Nanoparticle; PCA: Principal component analysis; PT: Prothrombin time; RBC: Red blood cell; ROS: Reactive oxygen species; SCN: Suprachiasmatic nucleus; SWCNT: Single-walled carbon nanotubes; UPLC: Ultra-pressure liquid chromatography; T1: Time point $1=24$ hours after the last NP administration; T2: Time point $2=8$ weeks after the last NP administration; TEM: Transmission electron microscopy; $\mathrm{TiO}_{2}$ : Titanium dioxide; TNF-a: Tumor necrosis factor alpha; UFP: Ultrafine particles; WBC: White blood cell; XRD: X-ray diffractogram; ZnO: Zinc oxide.

\section{Competing interests}

The authors declare that they have no competing interests.

\section{Authors' contributions}

$\mathrm{KL}$ prepared the NP solution. KL and SS exposed all mice to the NPs. Mice were sacrificed and samples were prepared by $\mathrm{KL}$. DN and $\mathrm{KL}$ prepared the samples for GSSG and GSH measurements. DN and KP optimized the protocol for GSSG and GSH measurements. KP performed the GSSG and GSH measurements. SVK and $\mathrm{BH}$ measured the hemostasis parameters. HS performed the statistical analysis. $\mathrm{PH}, \mathrm{MFH}, \mathrm{BH}$, and $\mathrm{KL}$ participated in the design of the study. All authors approved the final manuscript.

\section{Acknowledgements}

This work was financially supported by the "Engineered Nanoparticles Risk Assessment" (ENPRA) project (seventh framework programme) and the IWT (Grant number 101061).

\section{Author details}

'Department of Public Health and Primary Care, Occupational and Environmental Toxicology, KU Leuven, Leuven, Belgium. ²Department of Cardiovascular sciences, Center for Molecular and Vascular Biology, KU Leuven, Leuven, Belgium. ${ }^{3}$ Department of Public Health and Primary Care, Laboratory for Occupational and Environmental Hygiene, KU Leuven, Leuven, Belgium.

Received: 10 July 2014 Accepted: 29 October 2014

Published online: 14 November 2014

\section{References}

1. Hubbs AF, Mercer RR, Benkovic SA, Harkema J, Sriram K, Schwegler-Berry D, Goravanahally MP, Nurkiewicz TR, Castranova V, Sargent LM: Nanotoxicology-a pathologist's perspective. Toxicol Pathol 2011, 39:301-324. 
2. Nemmar A, Hoylaerts MF, Hoet PH, Vermylen J, Nemery B: Size effect of intratracheally instilled particles on pulmonary inflammation and vascular thrombosis. Toxicol Appl Pharmacol 2003, 186:38-45.

3. Bauer M, Moebus S, Mohlenkamp S, Dragano N, Nonnemacher M, Fuchsluger M, Kessler C, Jakobs H, Memmesheimer M, Erbel R, Jockel KH, Hoffmann B: Urban particulate matter air pollution is associated with subclinical atherosclerosis: results from the HNR (Heinz Nixdorf Recall) study. J Am Coll Cardiol 2010, 56:1803-1808

4. Peters A, Dockery DW, Muller JE, Mittleman MA: Increased particulate air pollution and the triggering of myocardial infarction. Circulation 2001, 103:2810-2815.

5. Baccarelli A, Martinelli I, Pegoraro V, Melly S, Grillo P, Zanobetti A, Hou L, Bertazzi PA, Mannucci PM, Schwartz J: Living near major traffic roads and risk of deep vein thrombosis. Circulation 2009, 119:3118-3124.

6. Brook RD, Rajagopalan S, Pope CA III, Brook JR, Bhatnagar A, Diez-Roux AV, Holguin F, Hong Y, Luepker RV, Mittleman MA, Peters A, Siscovick D, Smith SC Jr, Whitsel L, Kaufman JD: Particulate matter air pollution and cardiovascular disease: An update to the scientific statement from the American Heart Association. Circulation 2010, 121:2331-2378.

7. Jacobs L, Emmerechts J, Mathieu C, Hoylaerts MF, Fierens F, Hoet PH, Nemery B, Nawrot TS: Air pollution related prothrombotic changes in persons with diabetes. Environ Health Perspect 2010, 118:191-196.

8. Kwon HJ, Cho SH, Nyberg F, Pershagen G: Effects of ambient air pollution on daily mortality in a cohort of patients with congestive heart failure. Epidemiology 2001, 12:413-419.

9. Pope CA III: Epidemiology of fine particulate air pollution and human health: biologic mechanisms and who's at risk? Environ Health Perspect 2000, 108(Suppl 4):713-723.

10. LeBlanc AJ, Moseley AM, Chen BT, Frazer D, Castranova V, Nurkiewicz TR: Nanoparticle inhalation impairs coronary microvascular reactivity via a local reactive oxygen species-dependent mechanism. Cardiovasc Toxicol 2010, 10:27-36.

11. Nemmar A, Hoylaerts MF, Hoet PH, Dinsdale D, Smith T, Xu H, Vermylen J, Nemery B: Ultrafine particles affect experimental thrombosis in an in vivo hamster model. Am J Respir Crit Care Med 2002, 166:998-1004.

12. Cao $Y$, Jacobsen NR, Danielsen $P H$, Lenz AG, Stoeger $T$, Loft $S$, Wallin $H$, Roursgaard M, Mikkelsen L, Moller P: Vascular Effects of Multiwalled Carbon Nanotubes in Dyslipidemic ApoE-/- Mice and Cultured Endothelial Cells. Toxicol Sci 2014, 138:104-116.

13. Li Z, Hulderman T, Salmen R, Chapman R, Leonard SS, Young SH, Shvedova A, Luster MI, Simeonova PP: Cardiovascular effects of pulmonary exposure to single-wall carbon nanotubes. Environ Health Perspect 2007, 115:377-382.

14. Lowrey PL, Takahashi JS: Mammalian circadian biology: elucidating genome-wide levels of temporal organization. Annu Rev Genomics Hum Genet 2004, 5:407-441.

15. Panda S, Antoch MP, Miller BH, Su Al, Schook AB, Straume M, Schultz PG Kay SA, Takahashi JS, Hogenesch JB: Coordinated transcription of key pathways in the mouse by the circadian clock. Cell 2002, 109:307-320.

16. Dardente $\mathrm{H}$, Cermakian N: Molecular circadian rhythms in central and peripheral clocks in mammals. Chronobiol Int 2007, 24:195-213.

17. Somanath PR, Podrez EA, Chen J, Ma Y, Marchant K, Antoch M, Byzova TV: Deficiency in core circadian protein Bmal1 is associated with a prothrombotic and vascular phenotype. J Cell Physiol 2010, 226:132-140.

18. Anea CB, Zhang M, Stepp DW, Simkins GB, Reed G, Fulton DJ, Rudic RD: Vascular disease in mice with a dysfunctional circadian clock. Circulation 2009, 119:1510-1517.

19. Hemmeryckx B, Van Hove CE, Fransen P, Emmerechts J, Kauskot A, Bult H, Lijnen HR, Hoylaerts MF: Progression of the prothrombotic state in aging Bmal1-deficient mice. Arterioscler Thromb Vasc Biol 2011, 31:2552-2559.

20. Kondratov RV, Kondratova AA, Gorbacheva WY, Vykhovanets OV, Antoch MP: Early aging and age-related pathologies in mice deficient in BMAL1, the core componentof the circadian clock. Genes Dev 2006, 20:1868-1873.

21. Kondratov RV, Vykhovanets O, Kondratova AA, Antoch MP: Antioxidant $\mathrm{N}$-acetyl-L-cysteine ameliorates symptoms of premature aging associated with the deficiency of the circadian protein BMAL1. Aging (Albany NY) 2009, 1:979-987.

22. Droge $W$ : Free radicals in the physiological control of cell function. Physiol Rev 2002, 82:47-95.

23. Guntur AR, Kawai M, Le P, Bouxsein ML, Bornstein S, Green CB, Rosen CJ: An essential role for the circadian-regulated gene nocturnin in osteogenesis: the importance of local timekeeping in skeletal homeostasis. Ann N Y Acad Sci 2011, 1237:58-63.

24. Chatterjee S, Nam D, Guo B, Kim JM, Winnier GE, Lee J, Berdeaux R, Yechoor VK, Ma K: Brain and muscle Arnt-like 1 is a key regulator of myogenesis. J Cell Sci 2013, 126:2213-2224.

25. Shi SQ, Ansari TS, McGuinness OP, Wasserman DH, Johnson CH: Circadian disruption leads to insulin resistance and obesity. Curr Biol 2013 23:372-381.

26. Park EJ, Roh J, Kim SN, Kang MS, Han YA, Kim Y, Hong JT, Choi K: A single intratracheal instillation of single-walled carbon nanotubes induced early lung fibrosis and subchronic tissue damage in mice. Arch Toxicol 2011, 85:1121-1131.

27. Shvedova AA, Kisin E, Murray AR, Johnson VJ, Gorelik O, Arepalli S, Hubbs AF, Mercer RR, Keohavong P, Sussman N, Jin J, Yin J, Stone S, Chen BT, Deye G, Maynard A, Castranova V, Baron PA, Kagan VE: Inhalation vs. aspiration of single-walled carbon nanotubes in C57BL/6 mice: inflammation, fibrosis, oxidative stress, and mutagenesis. Am J Physiol Lung Cell Mol Physiol 2008, 295:L552-L565.

28. Adamcakova-Dodd A, Stebounova LV, Kim JS, Vorrink SU, Ault AP, O'shaughnessy PT, Grassian VH, Thorne PS: Toxicity assessment of zinc oxide nanoparticles using sub-acute and sub-chronic murine inhalation models. Part Fibre Toxicol 2014, 11:15

29. Cho WS, Duffin R, Poland CA, Howie SE, Macnee W, Bradley M, Megson IL, Donaldson K: Metal oxide nanoparticles induce unique inflammatory footprints in the lung: important implications for nanoparticle testing. Environ Health Perspect 2010, 118:1699-1706.

30. Chen JK, Ho CC, Chang H, Lin JF, Yang CS, Tsai MH, Tsai HT, Lin P: Particulate nature of inhaled zinc oxide nanoparticles determines systemic effects and mechanisms of pulmonary inflammation in mice. Nanotoxicology 2014, Feb 21. [Epub ahead of print].

31. Vogelmeier C, Konig G, Bencze K, Fruhmann G: Pulmonary involvement in zinc fume fever. Chest 1987, 92:946-948.

32. Plum LM, Rink $L$, Haase $H$ : The essential toxin: impact of zinc on human health. Int J Environ Res Public Health 2010, 7:1342-1365.

33. Mills CF: Zinc in Human Biology. London: Springer; 1989.

34. Ibs KH, Rink L: Zinc-altered immune function. J Nutr 2003, 133:1452S-1456S

35. Jensen SA, Kembouche Y, Nielsen SH, Bilanicovà D, Brunelli A, Pojana G, Marcomini A, Kofoed-Sorensen $\mathrm{V}$, Clausen PA: In vitro sedimentation rates, dissolution and hydrochemical reactivity of the ENPRA nanomaterials; 2013.

36. Gibbs JE, Blaikley J, Beesley S, Matthews L, Simpson KD, Boyce SH, Farrow SN, Else KJ, Singh D, Ray DW, Loudon AS: The nuclear receptor REV-ERBalpha mediates circadian regulation of innate immunity through selective regulation of inflammatory cytokines. Proc Natl Acad Sci U S A 2012, 109:582-587

37. Curtis AM, Bellet MM, Sassone-Corsi P, O'Neill LA: Circadian clock proteins and immunity. Immunity 2014, 40:178-186.

38. Guo M, Li D, Zhao M, Zhang Y, Deng X, Geng D, Li R, Sun X, Gu H, Wan R: $\mathrm{NH} 2+$ implantations induced superior hemocompatibility of carbon nanotubes. Nanoscale Res Lett 2013, 8:205.

39. Meng J, Cheng X, Liu J, Zhang W, Li X, Kong H, Xu H: Effects of long and short carboxylated or aminated multiwalled carbon nanotubes on blood coagulation. PLoS One 2012, 7:e38995

40. Sachar S, Saxena RK: Cytotoxic effect of poly-dispersed single walled carbon nanotubes on erythrocytes in vitro and in vivo. PLoS One 2011, 6:e22032.

41. Elgrabli D, Floriani M, Bella-Gallart S, Meunier L, Gamez C, Delalain P, Rogerieux F, Boczkowski J, Lacroix G: Biodistribution and clearance of instilled carbon nanotubes in rat lung. Part Fibre Toxicol 2008, 5:20.

42. Muller J, Huaux F, Moreau N, Misson P, Heilier JF, Delos M, Arras M, Fonseca A, Nagy JB, Lison D: Respiratory toxicity of multi-wall carbon nanotubes. Toxicol Appl Pharmacol 2005, 207:221-231.

43. Portillo K, Martinez-Rivera C, Ruiz-Manzano J: Anaemia in chronic obstructive pulmonary disease. Does it really matter? Int J Clin Pract 2013, 67:558-565.

44. John M, Hoernig S, Doehner W, Okonko DD, Witt C, Anker SD: Anemia and inflammation in COPD. Chest 2005, 127:825-829.

45. Cote C, Zilberberg MD, Mody SH, Dordelly L, Celli B: Haemoglobin level and its clinical impact in a cohort of patients with COPD. Eur Respir J 2007, 29:923-929.

46. Portillo K, Belda J, Anton P, Casan P: [High frequency of anemia in COPD patients admitted in a tertiary hospital]. Rev Clin Esp 2007, 207:383-387.

47. Weiss G, Goodnough LT: Anemia of chronic disease. N Engl J Med 2005, 352:1011-1023. 
48. Koj A: Initiation of acute phase response and synthesis of cytokines. Biochim Biophys Acta 1996, 1317:84-94.

49. Kannel WB, Wolf PA, Castelli WP, D'Agostino RB: Fibrinogen and risk of cardiovascular disease. The Framingham Study. JAMA 1987, 258:1183-1186.

50. Lowe G, Rumley A, Norrie J, Ford I, Shepherd J, Cobbe S, Macfarlane P, Packard C: Blood rheology, cardiovascular risk factors, and cardiovascular disease: the West of Scotland Coronary Prevention Study. Thromb Haemost 2000, 84:553-558.

51. Shannahan JH, Kodavanti UP, Brown JM: Manufactured and airborne nanoparticle cardiopulmonary interactions: a review of mechanisms and the possible contribution of mast cells. Inhal Toxicol 2012, 24:320-339.

52. Jun EA, Lim KM, Kim K, Bae ON, Noh JY, Chung KH, Chung JH: Silver nanoparticles enhance thrombus formation through increased platelet aggregation and procoagulant activity. Nanotoxicology 2011, 5:157-167.

53. Nemmar A, Hoet PH, Dinsdale D, Vermylen J, Hoylaerts MF, Nemery B: Diesel exhaust particles in lung acutely enhance experimental peripheral thrombosis. Circulation 2003, 107:1202-1208.

54. Zhu MT, Feng WY, Wang B, Wang TC, Gu YQ, Wang M, Wang Y, Ouyang H, Zhao YL, Chai ZF: Comparative study of pulmonary responses to nanoand submicron-sized ferric oxide in rats. Toxicology 2008, 247:102-111.

55. Yoshida T, Yoshioka Y, Tochigi S, Hirai T, Uji M, Ichihashi K, Nagano K, Abe Y, Kamada H, Tsunoda S, Nabeshi H, Higashisaka K, Yoshikawa T, Tsutsumi Y: Intranasal exposure to amorphous nanosilica particles could activate intrinsic coagulation cascade and platelets in mice. Part Fibre Toxicol 2013, 10:41.

56. Nemmar A, Nemery B, Hoet PH, Van RN, Hoylaerts MF: Silica particles enhance peripheral thrombosis: key role of lung macrophage-neutrophil cross-talk. Am J Respir Crit Care Med 2005, 171:872-879.

57. Si-Tahar M, Pidard D, Balloy V, Moniatte M, Kieffer N, Van DA, Chignard M: Human neutrophil elastase proteolytically activates the platelet integrin alphallbbeta3 through cleavage of the carboxyl terminus of the alphallb subunit heavy chain. Involvement in the potentiation of platelet aggregation. J Biol Chem 1997, 272:11636-11647.

58. Trumel C, Si-Tahar M, Balloy V, Chignard M, Chap H, Payrastre B, Plantavid M, Pidard D: Phosphoinositide 3-kinase inhibition reverses platelet aggregation triggered by the combination of the neutrophil proteinases elastase and cathepsin G without impairing alpha(Illb)beta(3) integrin activation. FEBS Lett 2000, 484:184-188.

59. Hemmeryckx B, Hoylaerts MF, Lijnen HR: Effect of premature aging on murine adipose tissue. Exp Gerontol 2012, 47:256-262.

60. Libby P: Inflammation in atherosclerosis. Nature 2002, 420:868-874.

61. Bunger MK, Wilsbacher LD, Moran SM, Clendenin C, Radcliffe LA, Hogenesch JB, Simon MC, Takahashi JS, Bradfield CA: Mop3 is an essential component of the master circadian pacemaker in mammals. Cell 2000, 103:1009-1017.

62. Kermanizadeh A, Pojana G, Gaiser BK, Birkedal R, Bilanicova D, Wallin H, Jensen KA, Sellergren B, Hutchison GR, Marcomini A, Stone V: In vitro assessment of engineered nanomaterials using a hepatocyte cell line: cytotoxicity, pro-inflammatory cytokines and functional markers. Nanotoxicology 2012, 7:301-313.

63. Anon: ENPRA final report summary. Assessed on 14-10-14, (http://cordis. europa.eu/result/rcn/56040_en.html).

doi:10.1186/s12989-014-0061-5

Cite this article as: Luyts et al.: Pulmonary and hemostatic toxicity of multi-walled carbon nanotubes and zinc oxide nanoparticles after pulmonary exposure in Bmal1 knockout mice. Particle and Fibre Toxicology 2014 11:61

\section{Submit your next manuscript to BioMed Central and take full advantage of:}

- Convenient online submission

- Thorough peer review

- No space constraints or color figure charges

- Immediate publication on acceptance

- Inclusion in PubMed, CAS, Scopus and Google Scholar

- Research which is freely available for redistribution 